\title{
Effects of lipopolysaccharide and cyclosporin on the endocrine control of ovarian function
}

\author{
T. Shakil, A. Snell and S. A. Whitehead \\ Department of Physiology, St George's Hospital Medical School, Cranmer Terrace, \\ London SW17 ORE, UK
}

\begin{abstract}
The effects of stimulating the immune system with lipopolysaccharide (LPS) or suppressing the immune system with cyclosporin (CS) on reproductive functions in the female rat were investigated. Animals were either treated acutely with LPS $\left(2 \mathrm{mg} \mathrm{kg}^{-1}\right)$ or cyclosporin $\left(20 \mathrm{mg} \mathrm{kg}^{-1}\right)$ on dioestrus day 1 and 2 or treated chronically over a period of 6 days (on alternate days with LPS, daily with CS). Chronic LPS treatment induced a state of constant dioestrus and decreased circulating concentrations of progesterone and oestradiol. Chronic CS treatment induced some irregularity in the 4-day vaginal smear pattern in a minority of animals and, while it had no effect on circulating concentrations of progesterone, oestradiol concentrations were suppressed compared with those measured in pro-oestrous animals. LH responses to $\mathrm{GnRH}$ were reduced in both perifused pituitary fragments and cultured pituitary cells obtained from animals pretreated with either LPS or CS. In contrast, a low dose of LPS $\left(20 \mu \mathrm{g} \mathrm{kg}^{-1}\right)$ given over 6 days did not disrupt ovarian cycles and reduced, but did not abolish, the second phase primed LH response. Neither drug had a direct effect on the pituitary LH responses to GnRH, except that pituitary cells exposed to high doses of CS for periods greater than $48 \mathrm{~h}$ did show attenuated LH responses to GnRH. This finding was not paralleled with high doses of LPS. The differential count of ovarian follicles from histological studies showed that LPS treatment was associated with significantly fewer large preovulatory follicles, whereas animals treated with CS showed a similar distribution of follicular volumes compared with controls. Results suggest that the hypothalamic-pituitary control of ovarian function is impaired by both LPS and CS treatment, and LPS appears to have an additional effect in suppressing ovarian functions, possibly via an inhibitory action on steroidogenesis.
\end{abstract}

\section{Introduction}

A variety of immunoregulatory polypeptides have been implicated as modulators of endocrine and neuroendocrine secretions (Rothwell, 1991a). Most notable are the cytokines, particularly interleukin (IL)-1, IL-6 and tumour necrosis factor $\alpha$ (TNF- $\alpha$ ). While much work has focused on the interaction between the immune system and the adrenal axis, there is growing evidence that suggests that cytokines can modulate reproductive functions. Several studies have shown that IL-1, IL- 6 and TNF- $\alpha$ inhibit steroidogenesis in ovarian follicles and suppress the functional and morphological luteinization of cultured granulosa cells (Adashi, 1990). Direct effects of various cytokines on hormone secretion from cultured pituitary cells or perifused pituitary tissue have also been observed and, in general, cytokines are reported to stimulate $\mathrm{LH}$ secretion (Beach et al., 1989; Spangelo et al., 1989; Yamaguchi et al., 1990a). In contrast, parallel in vivo and in vitro experiments (Rivier and Vale, 1990; Kalra et al., 1990) suggest that IL-1 inhibits the release of $\mathrm{LH}$ by suppressing the secretion of GnRH.

Received 8 February 1993.
Although these experiments demonstrate pharmacological effects of IL-I, IL- 6 and TNF- $\alpha$ on the secretion of reproductive hormones, little is known about the response of the reproductive system to an infection. Macrophages and monocytes release IL-1 $\beta$ and TNF- $\alpha$ when challenged with a bacterial endotoxin such as lipopolysaccharide (Raetz et al., 1991) and IL-1 $\beta$ can stimulate the release of IL- 6 from pituitary cells (Spangelo et al., 1991). Furthermore, there is evidence that the brain (Rothwell, 1991b) and pituitary gland (Koenig et al., 1990) are sites of IL- $1 \beta$ and IL- 6 production. On the basis of this evidence, we investigated various parameters of reproductive function after activating the immune system with lipopolysaccharide (LPS). In parallel the effects of immunosuppression with cyclosporin (CS) were also investigated.

\section{Materials and Methods}

Adult female Porton Wistar rats weighing between 200 and $250 \mathrm{~g}$ were housed under controlled lighting conditions (lights on $06.00 \mathrm{~h}$ to $18.00 \mathrm{~h})$ and temperature $\left(20^{\circ} \mathrm{C}\right)$. They had free access to food and water. Daily vaginal smears were taken and 
only those showing at least two consecutive 4-day oestrous cycles were used for experiments.

\section{Drug treatments}

Rats were treated either acutely (2 days) or chronically (6 days) with LPS (E. coli serotype 0128:B12, Sigma, Poole, Dorset) or CS (Sandoz, Basel) and both drugs were dissolved in saline so that the final volume of injection remained constant $(0.5 \mathrm{ml})$. Daily vaginal smears were continued throughout the treatment period. For the acute treatments, animals were injected s.c. with either $2 \mathrm{mg} \mathrm{LPS} \mathrm{kg}^{-1}$ or $20 \mathrm{mg} \mathrm{CS} \mathrm{kg}^{-1}$ body weight on dioestrous day $\mathrm{I}$ (day $\mathrm{I}$ ) and day 2 (day 2). Chronic treatment was also started on day $\mathrm{I}$ and continued for 6 days until the expected day 2 of the next oestrous cycle. Animals treated with LPS were injected on days I, 3 and 5 with $2 \mathrm{mg} \mathrm{LPS} \mathrm{kg}{ }^{-1}$ and on day 6 with $1 \mathrm{mg} \mathrm{LPS} \mathrm{kg}{ }^{-1}$ or with $20 \mu \mathrm{g} \mathrm{LPS} \mathrm{kg}^{-1}$ on all treatment days. Treatment on alternate days was adopted because it is well known that tolerance to the drug can develop. Rats chronically treated with CS received

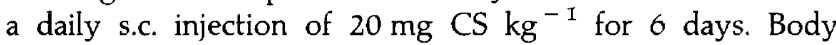
weights were recorded at the beginning, middle and end of the chronic treatment schedules.

On the expected morning of pro-oestrus, rats were stunned and decapitated and blood was collected for subsequent hormone analysis. Pituitary glands were dissected out and the tissue was either used for pituitary perifusions or for pituitary cell cultures. At the same time the ovaries and uteri were dissected out and weighed.

\section{Pituitary perifusions}

Hemi-pituitary glands were quartered and placed in $200 \mu \mathrm{l}$ perspex chambers and perifused with Krebs Ringer bicarbonate (KRB) containing $0.2 \% \mathrm{BSA}$ and $0.2 \%$ glucose. The tissue fragments were perifused with KRB at a rate of $150 \mu \mathrm{lmin}^{-1}$ and the medium was constantly gassed with $95 \% \mathrm{O}_{2}$ and $5 \%$ $\mathrm{CO}_{2}$ and maintained at $37^{\circ} \mathrm{C}$. After a $2 \mathrm{~h}$ stabilization period, two fractions were collected for $20 \mathrm{~min}$ each before the medium was changed to KRB containing $50 \mathrm{ng}$ synthetic $\mathrm{GnRH} \mathrm{ml}{ }^{-1}$ (Peninsula Laboratories, Merseyside). The direct effects of LPS and CS on GnRH-induced LH responses in vitro were tested by perifusing pituitary fragments with $\mathrm{KRB}$ containing either $100 \mathrm{ng} \mathrm{LPS} \mathrm{ml}^{-1}$ or $20 \mu \mathrm{g} \mathrm{CS} \mathrm{ml}^{-1}$ throughout the course of the experiment. All fractions were stored at $-20^{\circ} \mathrm{C}$ until assayed for $\mathrm{LH}$.

\section{Pituitary cell cultures}

Anterior pituitary glands (3-4 for each experimental and control group) were washed in Earle's balanced salt solution and cut into small tissue blocks using a sterile scalpel blade. The tissue fragments were enzymatically dispersed in $10 \mathrm{ml}$ Earle's balanced salt solution containing $0.3 \% \mathrm{BSA}, 0.25 \%$ trypsin and $0.05 \%$ DNase (all from Sigma). During dispersion the tissue was maintained at $37^{\circ} \mathrm{C}$ in an enclosed, humidified atmosphere of $5 \% \mathrm{CO}_{2}$ in air. Every $10 \mathrm{~min}$ the tissue was drawn in and out of a Pasteur pipette to increase the rate of dispersion. After $45 \mathrm{~min}$, the tissue was centrifuged for $5 \mathrm{~min}$ at $475 \mathrm{~g}$ and resuspended in fresh dispersion medium and the procedure was then repeated. The dispersed cells were washed twice with culture medium before being counted and diluted to give a single cell suspension of $5 \times 10^{5}$ cells ml ${ }^{-1}$. Aliquots $1 \mathrm{ml}$, were dispensed into multiwell $(24 \times 16 \mathrm{~mm})$ tissue culture plates (Philip Harris, London). The culture medium was Dulbecco's Modified Eagle's Medium (DMEM F-12) containing $5 \%$ fetal calf serum (Life Technologies, Paisley), $1 \%$ non-essential amino acids (Life Technologies), $0.1 \mathrm{mmol}$ glutamine $1^{-1}$ (freshly added, Sigma), $0.2 \%$ glucose, $100 \mathrm{U}$ penicillin $G \mathrm{ml}^{-1} / 100 \mu \mathrm{g}$ streptomycin sulfate $\mathrm{ml}^{-1}$ (Life Technologies) and $2.5 \mu \mathrm{g}$ fungizone $\mathrm{ml}^{-1}$ (Life Technologies). Initial cell viability was $>95 \%$, as measured by the trypan blue exclusion test, falling to $75-80 \%$ after 5 days in culture.

Cells were incubated in a humidified atmosphere of air and $5 \% \mathrm{CO}_{2}$ at $37^{\circ} \mathrm{C}$ for $48 \mathrm{~h}$ before the medium was changed. Cells were then incubated for $2 \mathrm{~h}$ to evaluate basal $\mathrm{LH}$ secretion. The medium was then supplemented with 0.5 or $5 \mathrm{ng} \mathrm{GnRH} \mathrm{ml}{ }^{-1}$. After $30 \mathrm{~min}$, a $200 \mu \mathrm{l}$ sample was taken from the culture medium and a final sample was taken after $2 \mathrm{~h}$. Various doses of LPS and CS were added to the cultures either at the time when the cells were initially plated out or during the $\mathrm{GnRH}$ challenge, to test the in vitro effects of these drugs. Samples were stored at $-20^{\circ} \mathrm{C}$ and in the subsequent analysis of results correction was made for the reduced volume at the $2 \mathrm{~h}$ sample collection.

\section{Ovarian histology}

Ovaries were fixed in Bouin's solution for $18 \mathrm{~h}$. After standardized dehydration, clearing and embedding in paraffin wax, $12 \mu \mathrm{m}$ serial sections of one randomly chosen ovary from each rat were cut and stained with haematoxylin and eosin. Follicular volumes were measured using the method of Welschen (1973). Briefly, this involved measuring two diameters of the follicle at right angles to each other in the section in which the nucleolus was found. Volumes were then calculated from the mean of these two measurements and classified in accordance with the classes shown in Fig. 7. Only follicles with a volume between $250 \times 10^{5} \mu \mathrm{m}^{3}$ and $499 \times 10^{5} \mu \mathrm{m}^{3}$ (360-455 $\mu \mathrm{m}$ mean diameter) were included in the analysis and follicles $>500 \times 10^{5} \mu \mathrm{m}^{3}$ were considered to be preovulatory follicles (Welschen and Rutte, 1971). Cyst-like, thin-walled follicles or follicles containing pycnotic granulosa cells, nude oocytes or oocytes without a nucleus were considered atretic. The numbers and sizes of atretic follicles were analysed separately from the healthy follicles.

\section{Assays and statistical analyses}

LH concentrations in serum, perifusate and cell culture medium were measured by radioimmunoassay using the procedure outlined by NIDDK and are expressed in terms of ng rat LH RP $3 \mathrm{ml}^{-1}$. Inter- and intra-assay coefficients of variation were $9.2 \%$ and $7.9 \%$, respectively, and assay sensitivity was $0.6 \mathrm{ng} \mathrm{ml}^{-1}$. Serum concentrations of oestradiol and progesterone were measured with direct radioimmunoassay kits (Immunodiagnostic Systems Ltd, Tyne and Wear) which have been validated for measuring steroids in both plasma and 
Table 1. Concentrations of oestradiol, progesterone and creatinine in plasma and the number of preovulatory follicles measured in rats treated for 6 days with either lipopolysaccharide $\left(2 \mathrm{mg} \mathrm{kg}{ }^{-1}\right)$, cyclosporin $\left(20 \mathrm{mg} \mathrm{kg}^{-1}\right)$ or in saline treated controls

\begin{tabular}{lcccc}
\hline & $\begin{array}{c}\text { Oestradiol } \\
\left(\mathrm{pg} \mathrm{ml}^{-1}\right) \\
(n=6)\end{array}$ & $\begin{array}{c}\text { Progesterone } \\
\left(\mathrm{ng} \mathrm{ml}^{-1}\right) \\
(n=6)\end{array}$ & $\begin{array}{c}\text { Creatinine } \\
\left.(\mathrm{mg} \mathrm{dl})^{-1}\right) \\
(n=6)\end{array}$ & $\begin{array}{c}\text { Number of } \\
\text { preovulatory follicles } \\
\left(>500 \times 10^{5} \mu \mathrm{m}^{3}\right) \\
(n=4)\end{array}$ \\
\hline LPS & $24.4 \pm 7.9^{*}$ & $6.81 \pm 1.6^{*}$ & $1.24 \pm 0.01$ & $9.0 \pm 1.2$ \\
CS & $19.0 \pm 5.3^{*}$ & $17.08 \pm 4.8$ & $1.32 \pm 0.02$ & $4.75 \pm 2.7$ \\
Control & $86.8 \pm 26.8$ & $15.63 \pm 2.5$ & $1.18 \pm 0.01$ & $7.25 \pm 0.8$ \\
\hline
\end{tabular}

Values are means \pm SEM. LPS: lipopolysaccharide; CS: cyclosporin.

*Significantly different $(P<0.05)$ from the other group(s) (Gabriel's multiple comparison test).

culture medium. Crossreactivity of the oestradiol antiserum with oestrone and oestriol was $2.9 \%$ and $0.42 \%$, respectively, and inter- and intra-assay coefficients of variation were 12 and $5 \%$, respectively. For the progesterone antiserum, crossreactivity with $17 \alpha$-hydroxyprogesterone and pregnenolone was 2 and $0.3 \%$, respectively, and inter- and intra-assay coefficients of variation were 8 and $4 \%$, respectively. Plasma creatinine concentrations in CS, LPS and saline treated controls were measured with a colorimetric assay kit (Sigma). All results are expressed as means \pm SEM. Statistical comparisons of two groups were made with an unpaired $t$ test, but when more than two groups were being compared, a one-way analysis of variance followed by Gabriel's test was used. This multiple comparison test is suitable for groups of unequal sizes.

\section{Results}

\section{Drug toxicity}

A dose of $1 \mathrm{mg} \mathrm{LPS} \mathrm{kg}^{-1}$ body weight has been reported to induce a febrile attack in rats and thus rectal temperature was monitored 30,60, 90 and 120 min after s.c. administration of $2 \mathrm{mg} \mathrm{LPS}^{-1}$. Although five of the six animals so tested showed a small increase in rectal temperature (range $0.45-0.92^{\circ} \mathrm{C}$ ), similar increases were observed after saline treatment despite prior conditioning of the animals to the rectal probe. CS prevented the expected rise in body weight, whereas LPS-treated rats showed a typical increase during the 6-day treatment which was comparable to that of control animals. No overt behavioural changes were seen in the animals, even after chronic treatment with LPS. Similarly, CS treatment did not cause any overt behavioural side effects and measurement of plasma creatinine (an index of the nephrotoxic side effect of the drug) showed that plasma concentrations were well within the normal range for rats and not different from those measured in control and LPStreated rats (Table 1).

\section{Vaginal smears, ovarian and uterine weights}

Treatment with LPS disrupted oestrous cyclicity. All rats treated acutely on day 1 and day 2 had a dioestrous-type smear on the following day (expected pro-oestrus) and, in 13 of 14 animals treated with the high dose LPS for the 6-day treatment regimen, a state of constant dioestrus was recorded. Chronic treatment with the low dose LPS did not disrupt the regular vaginal smear pattern. In contrast, CS treatment did not consistently disrupt ovarian cycles. For the 2-day treatment, three of 12 animals failed to enter prooestrus and during the 6-day treatment vaginal smears were irregular in six of 14 animals. However, CS treatment did not cause a state of constant dioestrus as observed during LPS treatment.

There were no differences in ovarian weights between these three groups of animals, although the mean uterine weight was significantly lower in the LPS-treated groups compared with both CS-treated and control groups (Table 2).

\section{Pituitary responses to $\mathrm{GnRH}$}

Continuous perifusion of pituitary fragments with $\mathrm{GnRH}$ produced the typical biphasic response. During the first 20-40 min, the rate of LH secretion is lower than that observed in subsequent samples. This represents the first phase unprimed response. The higher rate of secretion represents the primed response. After the 2-day treatment with $2 \mathrm{mg} \mathrm{LPS} \mathrm{kg}^{-1}$, pituitary LH responses to a continuous GnRH challenge were reduced, while two injections of $20 \mathrm{mg} \mathrm{CS} \mathrm{kg}^{-1}$ had no significant effect on the LH responses (Fig. I). However, LH responses were virtually abolished in perifused pituitary glands obtained from rats chronically treated with either high-dose LPS or CS for 6 days (Fig. 2a, b), while the low dose LPS treatment $\left(20 \mu \mathrm{g} \mathrm{kg}^{-1}\right)$ resulted in a significant attenuation of the primed LH response (Fig. 2a). When LPS or CS was added to the perifusion medium at $100 \mathrm{ng} \mathrm{ml}^{-1}$ and $20 \mu \mathrm{g} \mathrm{ml}^{-1}$, respectively, there were no obvious impairments of the $\mathrm{LH}$ responses to GnRH (Fig. 3).

These results from perifusion studies were paralleled by observations on the primary cultures of pituitary cells obtained from rats chronically treated with LPS and CS. Pretreatment with both LPS and CS significantly reduced the LH responses to GnRH compared with saline treated controls, even though the cells had been in culture for $48 \mathrm{~h}$ before the GnRH challenge (Fig. $4 a, b$ ). In contrast, when LPS was added to the culture medium, no significant attenuation of GnRH-stimulated LH 
Table 2. Percentage changes in body weight recorded over 6-day treatment with either lipopolysaccharide $\left(2 \mathrm{mg} \mathrm{kg}{ }^{-1}\right)$ or cyclosporin $\left(20 \mathrm{mg} \mathrm{kg}^{-1}\right)$ or vehicle injected controls and the respective ovarian and uterine weights measured at autopsy

\begin{tabular}{lccc}
\hline Treatment & Ovarian weight $(\mathrm{mg})$ & Uterine weight $(\mathrm{mg})$ & Change in body weight $(\%)$ \\
\hline LPS $(n=10)$ & $43.8 \pm 2.5$ & $179.8 \pm 17.2^{*}$ & $6.98 \pm 1.09$ \\
CS $(n=12)$ & $46.1 \pm 2.0$ & $281.1 \pm 26.1$ & $-0.58 \pm 0.41^{*}$ \\
Control $(n=12)$ & $45.6 \pm 2.0$ & $320.9 \pm 18.6$ & $5.37 \pm 0.45$ \\
\hline
\end{tabular}

Values are means \pm SEM.

LPS: lipopolysaccharide; CS: cyclosporin.

$* P<0.005$ compared with the two other corresponding groups (Gabriel's multiple comparison test).

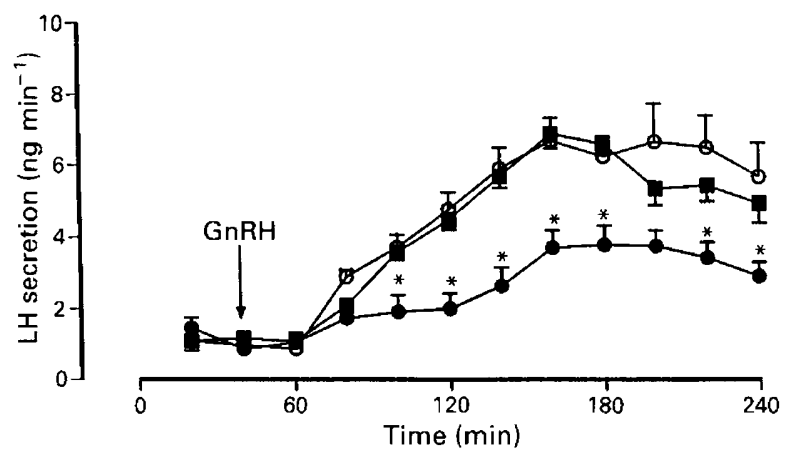

Fig. 1. LH secretion rates from perifused hemi-pituitary glands obtained from rats on the presumptive day of pro-oestrus. Animals were pretreated with lipopolysaccharide $\left(2 \mathrm{mg} \mathrm{kg}^{-1}\right)(0, n=8)$, cyclosporin $\left(20 \mathrm{mg} \mathrm{kg}^{-1}\right)(0, n=8)$ or vehicle alone $(\mathbf{\square}, n=7)$ on dioestrous day 1 and 2 . The arrow indicates the addition of $50 \mathrm{ng}$ $\mathrm{GnRH} \mathrm{ml} \mathrm{m}^{-1}$ to the Krebs Ringer bicarbonate (KRB) perifusing medium and values are means \pm SEM. *Significantly different $(P<0.05)$ from controls (Gabriel's multiple comparison test).

release was observed, even when pituitary cells were exposed to the drug throughout the entire period of culture (Fig. $5 \mathrm{a}, \mathrm{b}$ ). However, high doses of CS $\left(10 \mu \mathrm{g}\right.$ and $\left.100 \mu \mathrm{g} \mathrm{ml}^{-1}\right)$ did attenuate $\mathrm{LH}$ responses to $\mathrm{GnRH}$, but only when the drug was added to the medium at the beginning of the culture period (Fig. 6a, b). CS did not affect LH responses when it was added only at the same time as the GnRH stimulus (Fig. 6a).

\section{Ovarian histology and steroidogenesis}

There were no significant differences in the mean number of preovulatory follicles counted in the ovaries of LPS or CS treated and control groups (Table 1). However, when the differential count of all follicles in four ovaries was compared with the differential count of one or other groups, a $\chi^{2}$ analysis of the contingency tables showed that LPS treatment was associated with a higher number of small preovulatory follicles and a lower number of large preovulatory follicles (Fig. 7). For the association with the control group $\chi^{2}=9.4, d . f .=3$, $P<0.02$ and with the CS treated groups $\chi^{2}=8.07, d . f .=3$, $P<0.05$. Parallel measurements of plasma oestradiol and progesterone showed that LPS treatment significantly reduced the circulating concentrations of both of these steroids (Table 1), although decreased concentrations of oestradiol were also seen in animals treated chronically with CS.
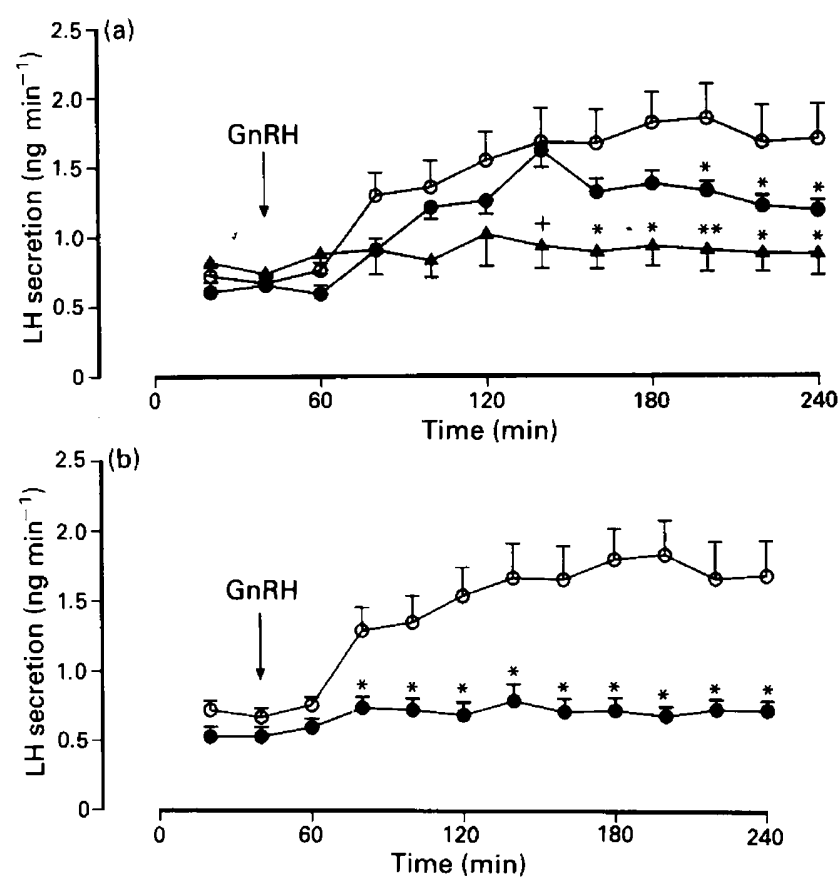

Fig. 2. LH secretion rates from perifused pituitary fragments obtained from rats pretreated for 6 days with either (a) lipopolysaccharide (LPS) or (b) cyclosporin (CS). In (a) animals were pretreated with $2 \mu \mathrm{g}$ LPS $\mathrm{kg}^{-1}(\boldsymbol{N}, n=7), 2 \mathrm{mg}$ LPS $\mathrm{kg}^{-1}(\boldsymbol{\Lambda}, n=7)$ or vehicle alone (O, $n=8$ ). In (b) animals were pretreated with $20 \mathrm{mg} \mathrm{CS} \mathrm{kg}^{-1}$ (O, $n=10$ ) or vehicle alone $(0, n=8)$. Arrows indicate the addition of $50 \mathrm{ng} \mathrm{GnRH} \mathrm{ml} \mathrm{m}^{-1}$ to the perifusing medium and values are means \pm SEM. In (a) $* P<0.05$ and $* * P<0.01$ compared with controls and $\pm P<0.005$ compared with both controls and low dose LPS (Gabriel's multiple comparison test). In (b) $* P<0.001$ compared with controls (Student's $t$ test).

\section{Discussion}

The results obtained in the study reported here support the evidence of interactions between the immune and reproductive systems. The observation that both stimulation and inhibition of the immune system resulted in marked changes of pituitary and ovarian function suggest that factors released from immune cells have an important modulatory role at one or more sites within the hypothalamic-pituitaryovarian axis. 


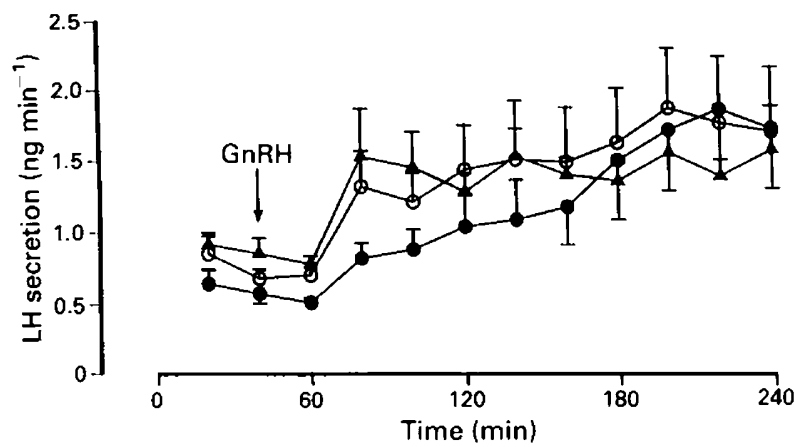

Fig. 3. LH secretion rates from hemi-pituitary glands obtained from pro-oestrous rats and perifused with medium containing either $100 \mathrm{ng}$

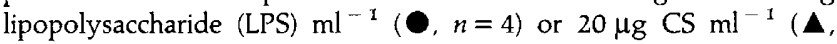
$n=4)$ or medium alone $(O, n=4)$. Drugs were present in the medium both during the stabilization period and during the whole period of sample collection. The arrow indicates the addition of $50 \mathrm{ng}$ $\mathrm{GnRH} \mathrm{ml}{ }^{-1}$ to the perifusing medium and values are means \pm SEM.

LPS has been shown to stimulate the release of cytokines (particularly IL-1 $\beta$, IL-6 and TNF- $\alpha$ ) from macrophages (Morrison and Ryan, 1987) and thus we considered that the drug might be a useful tool for investigating the effects of endogenously released cytokines on reproductive functions. Any in vivo studies are naturally compounded by the inability to separate individual components of a system and, in this instance, to distinguish between nonspecific side-effects of the drugs and their specific pharmacological actions. However, LPS itself had no direct effect on LH secretion either from perifused hemi-pituitary glands or from cultured pituitary cells, nor were there any overt behavioural signs or weight loss resulting from general illness during the course of treatment. Thus, it is not unreasonable to assume that the observed effects of the drug, at least in part, may have resulted from the release of endogenous cytokines both centrally and peripherally.

The loss of GnRH self-priming after acute LPS treatment could result from an inhibition of GnRH release, a direct effect of cytokines on the pituitary or a reduction in ovarian steroid feedback. IL-1 $\beta$ has been shown to reduce LH secretion (Rivier and Vale, 1990) and to attenuate the positive feedback effects of steroids in ovariectomized rats (Kalra $e t$ al., 1990) through a hypothalamic site of action rather than a direct action on the pituitary gland. Rivier and Vale (1990) also showed that intracerebroventricular injections of TNF- $\alpha$ suppressed LH release, but the potency of this cytokine was far less than that of IL-I $\beta$.

In contrast, IL-1 (Beach et al, 1989), IL-6 (Spangelo et al., 1989) and TNF- $\alpha$ (Yamaguchi et al., 1990a) have been shown to stimulate $\mathrm{LH}$ release from cultured pituitary cells. However, there is evidence that IL-I $\beta$ induces release of pituitary hormones by stimulating IL- 6 production from the folliculostellate cells of the anterior pituitary gland (Vankelecom $e t$ al, 1984; Yamaguchi et al., 1990b). Since endotoxin can stimulate the synthesis of IL-1 $\beta$ both in the brain (Rothwell, 1991b) and pituitary gland (Koenig et al., 1990), it would be anticipated that the LPS treatment could lead to disturbed regulation of gonadotrophin secretion. Indeed, intracerebroventricular administration of $2 \mu \mathrm{g}$ LPS inhibits LH release in castrated male rats (Rivier, 1990) and blocks ovulation when administered on
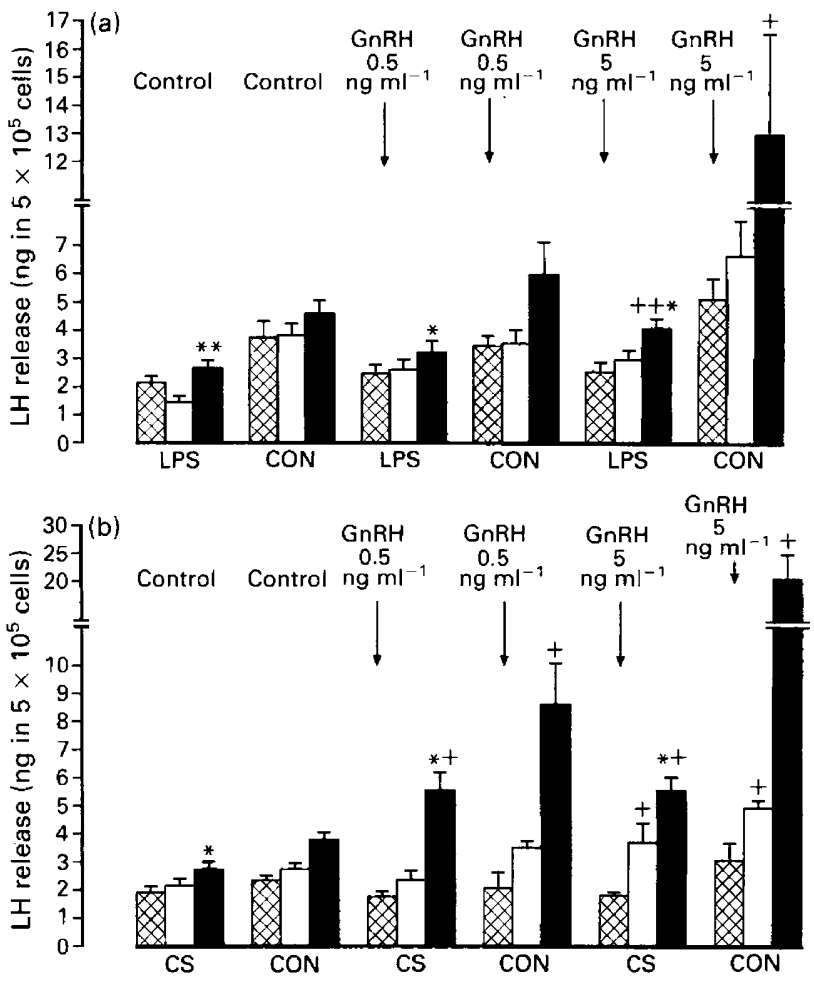

Fig. 4. $\mathrm{LH}$ release from $48 \mathrm{~h}$ cultured pituitary cells obtained from

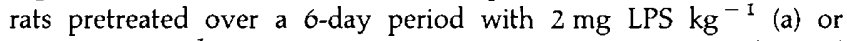
$20 \mathrm{mg} \mathrm{CS} \mathrm{kg}^{-1}$ (b) compared with control (CON) cultures obtained from animals pretreated with diluent alone. Hatched bars show mean concentrations of $\mathrm{LH}$ after a $2 \mathrm{~h}$ preincubation period and open and closed bars $30 \mathrm{~min}$ and $2 \mathrm{~h}$ after addition of 0.5 or $5 \mathrm{ng} \mathrm{GnRH} \mathrm{ml}{ }^{-1}$ to the culture medium as indicated by the arrows. The first two groups of histograms are the controls which received no GnRH stimulation. Values are means \pm SEM and for all groups $n>6$ from at least two separate experiments. Significantly different $\left({ }^{*} p<0.01\right)$ from the corresponding value seen in cells obtained from untreated animals and $\left({ }^{+} P<0.01\right)$ compared with mean basal LH release before the addition of GnRH to the medium (Student's $t$ test).

the morning of pro-oestrus (Rivier and Vale, 1990). However, a single intraperitoneal injection of LPS $(25 \mu \mathrm{g})$ at pro-oestrus did not affect ovulation the following day and Rivier and Vale concluded that high concentrations of IL- 1 in the brain were required to inhibit ovulation (Rivier and Vale, 1990).

This contention is in agreement with the results reported here after high and low dose LPS treatment. All rats treated on day 1 and day 2 with $2 \mathrm{mg} \mathrm{kg}^{-1}$ (approximately $500 \mu \mathrm{g}$ per rat) had dioestrous-type smears on the following day (expected pro-oestrus) and the pituitary responses were similar to those that we observed in pituitary glands obtained from dioestrous rats (unpublished results). Animals treated chronically with the same dose of LPS did not have an oestrous-type smear at the next expected oestrus and most animals entered a state of constant dioestrus. There was no significant first or second phase $\mathrm{LH}$ response to $\mathrm{GnRH}$ after this treatment. It was also of interest that pituitary cell cultures obtained from animals chronically treated with $2 \mathrm{mg}$ LPS $\mathrm{kg}^{-1}$ showed markedly attenuated $\mathrm{LH}$ responses to $\mathrm{GnRH}$, even though the cells had been cultured for $48 \mathrm{~h}$ prior to testing. Basal LH secretion in 


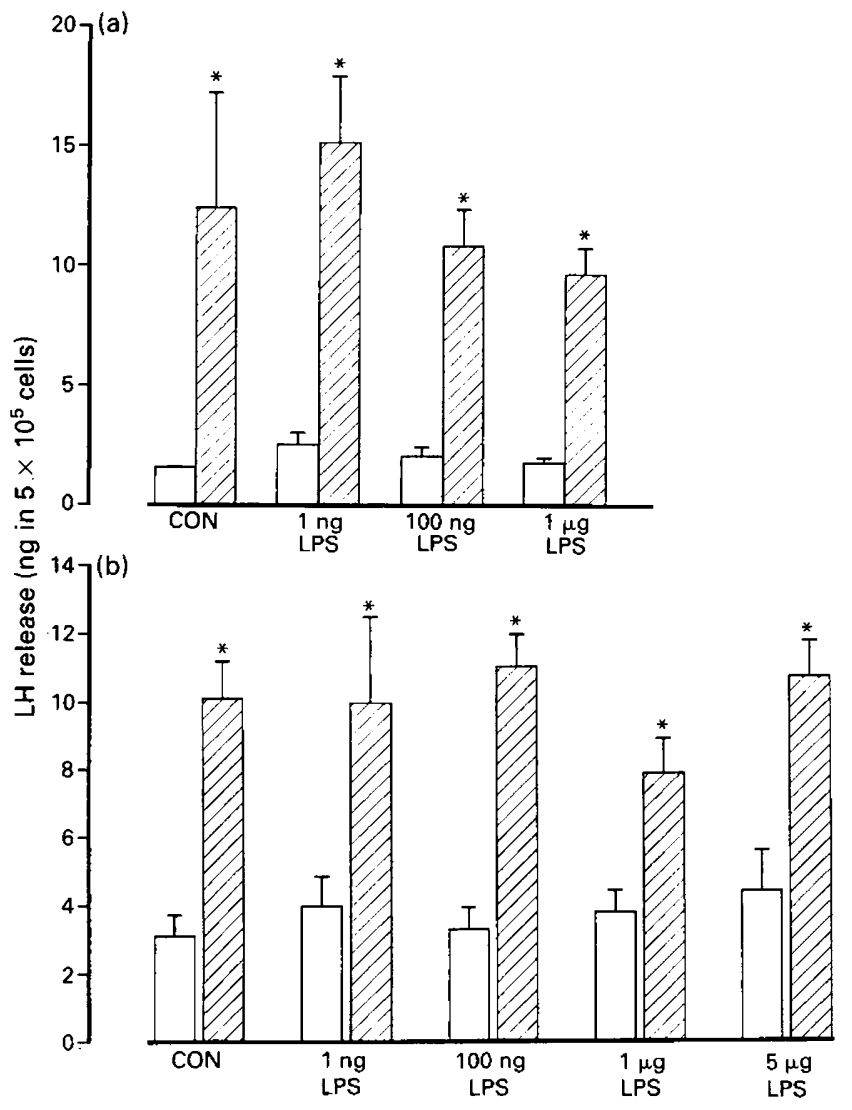

Fig. 5. LH release from cultured pituitary cells in the presence of lipopolysaccharide (LPS). In (a) LPS was added to the culture medium with GnRH at the start of the incubation period. In (b) LPS was added to the cells at the time of plating and after $48 \mathrm{~h}$ fresh medium also contained LPS. The doses of the drugs tested are indicated on the graphs. ( $\square$ ) mean levels \pm SEM of LH measured after the $2 \mathrm{~h}$ preincubation period; ( $\nabla$ ) LH responses measured $2 \mathrm{~h}$ after addition of $5 \mathrm{ng} \mathrm{GnRH} \mathrm{ml}{ }^{-1}$. For all observations $n=4-6$. *Significantly different $(P<0.001)$ from the preceding basal LH release (Student's $t$ test).

both preparations was similar to controls, which suggests that chronic treatment with LPS causes a complete downregulation of $\mathrm{GnRH}$ receptors. However, animals treated chronically with a low dose of LPS $\left(20 \mu \mathrm{g} \mathrm{kg}^{-1}\right.$, which is equivalent to approximately $5 \mu \mathrm{g}$ per rat) showed no disruption in vaginal cyclicity, even though there was some impairment of responses to $\mathrm{GnRH}$ in vitro in perifused pituitary glands. However, since there is a large functional reserve in pituitary LH responses in that ovulation can occur even if the normal preovulatory $\mathrm{LH}$ surge is markedly reduced (Grieg and Weisz, 1973), a reduction in pituitary responsiveness would not necessarily result in anovulation.

It is possible that impaired pituitary function was caused by the stress induced by LPS injection since corticosteroids can suppress basal and GnRH-stimulated LH release both in vivo and in vitro, an effect that is independent of gonadal steroids (Brann and Mahesh, 1991). Unfortunately, we were unable to obtain any valid comparisons in circulating concentrations of LH between control and experimental animals. LH concentrations are low both during dioestrus and during the morning

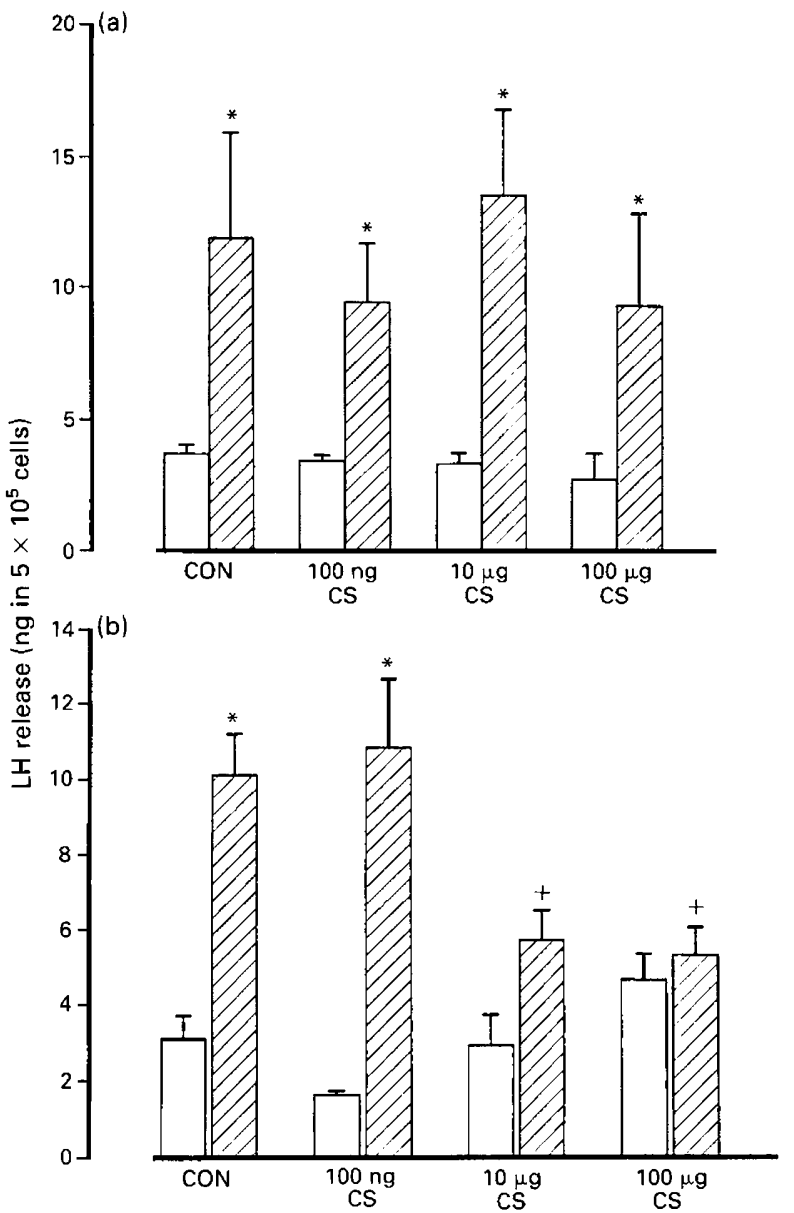

Fig. 6. LH release from cultured pituitary cells in the presence of cyclosporin (CS). In (a) CS was added to the culture medium with $\mathrm{GnRH}$ at the start of the incubation period. In (b) CS was added to the cells at the time of plating and after $48 \mathrm{~h}$ fresh medium also contained CS. The doses of the drugs tested are indicated on the graphs. ( $\square$ ) mean levels \pm SEM of LH measured after the $2 \mathrm{~h}$ preincubation period; $(\Theta) \mathrm{LH}$ responses measured $2 \mathrm{~h}$ after addition of $5 \mathrm{ng} \mathrm{GnRH} \mathrm{ml}{ }^{-1}$. For all observations $n=4-6$. Significantly different $\left({ }^{*} P<0.001\right)$ from preceding basal $\mathrm{LH}$ release and $\left({ }^{+} P<0.05\right)$ compared with corresponding value in control cultures (Student's $t$ test).

of pro-oestrus and typically values are about $0.6 \mathrm{ng} \mathrm{LH} \mathrm{ml}^{-1}$. Since $0.6 \mathrm{ng} \mathrm{LH} \mathrm{ml} \mathrm{m}^{-1}$ is the lower limit of sensitivity of our LH assay (the lowest point on our standard curve was $0.3 \mathrm{ng} \mathrm{ml}^{-1}$ ), comparisons of LH measurements around this value are not justified. Thus in vitro and in vivo release could not be compared.

There have been numerous studies showing that IL-I, IL-6 and TNF- $\alpha$ modulate steroidogenesis in both granulosa and thecal cells. Generally studies have shown that cytokines inhibit various steps of the steroidogenic pathway (Gottschall et al., 1988; Fukuoka et al., 1989; Andreani et al., 1991; Hurwitz et al., 1991a), although in intact ovarian follicles TNF- $\alpha$ has been shown to stimulate steroidogenesis (Roby and Terranova, 1990).

Since there are resident macrophages within the ovary and the ovary has been shown to be a site of both IL-1 $\beta$ (Hurwitz 


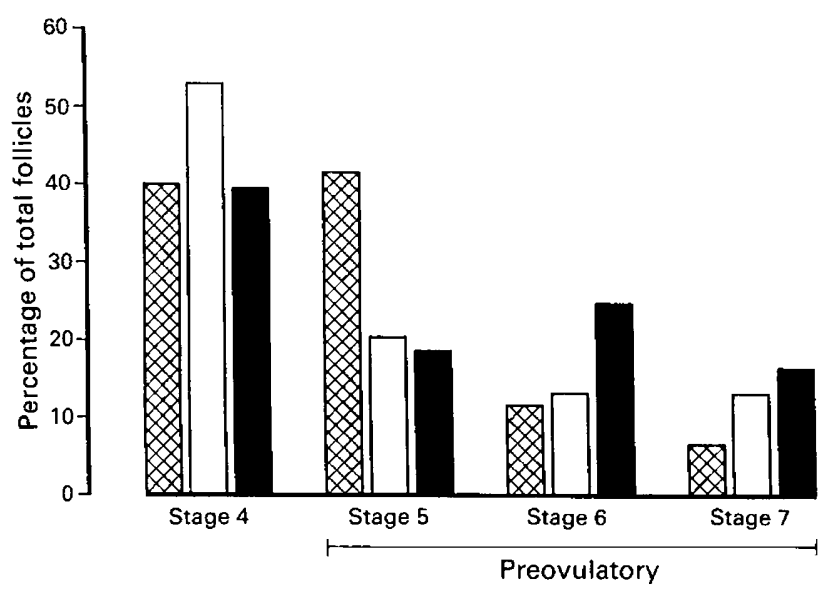

Fig. 7. The differential count of all follicles in four ovaries after chronic treatment with either (ipopolysaccharide (LPS) or ( $\square$ ) cyclosporin (CS) or ( $\mathbf{\square})$ saline controls. The histograms show the percentage of follicles within each group at different stages of development. The stage numbers correspond approximately to those defined by Mandl and Zuckerman (1952). Stage 4,

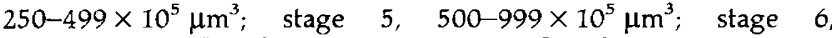

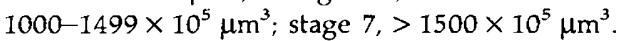

et al., 1991b) and TNF- $\alpha$ (Sancho-Tello et al., 1992a) production, it has been suggested that cytokines have an important paracrine function, even under non-pathological conditions (Adashi, 1990, Roby and Terranova, 1990). Thus it is likely that LPS treatment stimulated cytokine production in the ovary thereby disrupting normal steroidogenesis or follicular development or both processes. Recent studies showed that human granulosa-luteal cells exhibit an LPSbinding protein and that cells from follicular aspirates increase their synthesis and release of TNF- $\alpha$ in response to LPS (Sancho-Tello et al., 1992b). Similarly, LPS can stimulate TNF- $\alpha$ production by the rabbit corpus luteum and this response is highest at times of luteal regression, when the number of macrophages in the corpus luteum increases greatly (Bagavandoss et al., 1988, 1990). The present results suggest that LPS inhibited normal steroidogenesis. This contention is based on the following observations. First, after acute LPS treatment, pituitary responses to $\mathrm{GnRH}$ were attenuated compared with pro-oestrous controls implying a lack of oestrogen priming. Second, there were significantly fewer large preovulatory follicles in the LPS-treated rats compared with controls. Third, circulating concentrations of both oestradiol and progesterone were significantly reduced after chronic LPS treatment. Fourth, uterine weights were significantly lower than those of controls, and finally there was no direct effect of LPS on cultured pituitary cells.

It may seem somewhat paradoxical that both stimulation and inhibition of the immune system may produce similar results on pituitary responsiveness to GnRH both in perifused hemipituitary glands and in cultured pituitary cells. However, the fact that there was a divergence in other results observed in LPS- and CS-treated rats suggests that the drugs were disrupting reproductive functions in different ways. Thus, in CS-treated rats, there was no difference in the number of large preovulatory follicles or in uterine weights compared with controls, and while LPS treatment typically induced a state of constant dioestrus, CS either had no effect on the vaginal smear pattern or simply induced some irregularity in the 4-day cycle pattern. Furthermore, circulating progesterone concentrations were similar in CS-treated animals and controls, although oestradiol concentrations were significantly reduced and similar to those seen in LPS-treated animals. This reduction would suggest reduced gonadotrophic stimulation on the ovary and a consequent reduction of oestrogen priming on the pituitary hence the attenuated $\mathrm{LH}$ responses to $\mathrm{GnRH}$.

CS is known to be nephrotoxic, but measurement of concentrations of creatinine in plasma did not indicate any marked failure in kidney function during the course of treatment used in these experiments. However, the fact that animals failed to gain any weight does suggest that there were some side-effects of the drug. Studies on both rabbits and rats have shown that CS treatment induces a state of hypogonadism (Al-Chalabi, 1984; Sikka et al., 1988) and this effect has been attributed to a lack of stimulatory drive from the hypothalamus. However, Krüger et al. (1991) showed that CS acts directly on the testes to reduce the number of $\mathrm{LH}$ receptors and suppress heme formation. Together these effects caused an impairment of testicular function, reduction of testosterone secretion and an increase in concentrations of LH in plasma.

The present results do not indicate that acute CS treatment caused any marked impairment of ovarian function, although chronic treatment may lead to a loss of aromatase activity within the ovary and a lack of GnRH stimulation with a consequent downregulation of pituitary responsiveness. However, even a diminished LH signal to the ovary may be sufficient to sustain, at least, ovulatory cycles to some extent. In contrast, when pituitary cells were cultured for $48 \mathrm{~h}$ with CS, higher doses of the drug impaired LH responses to GnRH suggesting that $\mathrm{CS}$ can have a direct action on the pituitary gland.

These experiments were not designed to elucidate the precise site of action of immune factors on the hypothalamicpituitary-gonadal axis, but rather to obtain some data on the effects of stimulating and suppressing the immune system in vivo on various parameters of the female reproductive systems. These results will then serve as a basis for further investigations.

Overall, the results reported here suggest that LPS treatment can disrupt both gonadotrophin release and ovarian steroidogenesis, whereas the main action of CS is on the hypothalamic-pituitary unit. This finding is in agreement with our studies on cultured granulosa cells, which show that LPS pretreatment inhibits gonadotrophin-induced progesterone release, whereas CS pretreatment has no effect (authors' unpublished observations). Further parallel studies on cultured pituitary and granulosa cells are currently being undertaken to determine a more precise role of cytokines on the female reproductive system.

The authors wish to thank the Association of Commonwealth Universities. T. Shakil is a Commonwealth Scholar. They also thank the National Hormone and Pituitary Agency, NIDDK, for their gift of $\mathrm{LH}$ radioimmunoassay materials and $\mathrm{M}$. Lacey for excellent technical assistance. 


\section{References}

Adashi EY (1990) The potential relevance of cytokines to ovarian physiology: the emerging role of resident ovarian cells of the white blood cell series Endocrine Reviewos 11 454-464

Al-Chalabi WA (1984) Effect of cyclosporin A on the morphology and function of the ovary and fertility in the rabbit International joumal of Fertility $\mathbf{2 9}$ 218-223

Andreani CL, Payne DW, Packman JN, Resnick CE, Hurwitz A and Adashi EY (1991) Cytokine-mediated regulation of ovarian function Joumal of Biological Chemistry $2666761-6766$

Bagavandoss P, Kunkel SL, Wiggins RC and Keyes PL (1988) Tumor necrosis factor- $\alpha$ (TNF- $\alpha$ ) production and localization of macrophages and T lymphocytes in the rabbit corpus luteum Endocrinology 122 1185-1187

Bagavandoss P, Wiggins RC, Kunkel SL, Remick DG and Keyes PL (1990) Tumor necrosis factor production and accumulation of inflammatory cells in the corpus luteum of pseudopregnancy and pregnancy in rabbits Biology of Reproduction $42 \quad 367-376$

Beach JE, Smallridge RC, Kinzer CA, Bernton EW, Holaday JW and Fein G (1989) Rapid release of multiple hormones from rat pituitaries perifused with recombinant interleukin-1 Life Science 44 1-7

Brann DW and Mahesh VB (1991) Role of corticosteroids in female reproduction Faseb Journal 5 2691-2698

Fukuoka M, Yasuda K, Taii S, Takakura K and Mori T (1989) Interleukin-1 stimulates growth and inhibits progesterone secretion in cultures of porcine granulosa cells Endocrinology 124 884-890

Gottschall PE, Katsuura G, Dahl RR, Hoffmann ST and Arimura A (1988) Discordance in the effects of interleukin-1 on rat granulosa cell differentiation induced by follicle-stimulating hormone or activators of adenylate cyclase Biology of Reproduction 39 1074-1085

Grieg F and Weisz J (1973) Preovulatory levels of luteinizing hormone, the critical period and ovulation in rats Journal of Endocrinology 57 235-245

Hurwitz A, Payne DW, Packman JN, Andreani CL, Resnick CE, Hernandez ER and Adashi EY (1991a) Cytokine-mediated regulation of ovarian function: interleukin-1 inhibits gonadotropin-induced androgen biosynthesis Endocrinology 129 1250-1256

Hurwitz A, Ricciarelli E, Botero L, Rohan RM, Hernandez ER and Adashi EY (1991b) Endocrine and autocrine-mediated regulation of rat ovarian (thecainterstitial) interleukin-1 $\beta$ gene expression: gonadotrophin-dependent preovulatory acquisition Endocrinology 129 3427-3429

Kalra PS, Sahu A and Kalra SP (1990) Interleukin-1 inhibits the ovarian steroid-induced luteinizing hormone surge and release of hypothalamic luteinizing hormone-releasing hormone in rats Endocrinology $1262145-$ 2152

Koenig JI, Snow K, Clark BD, Toni R, Cannon JG, Shaw AR, Dinarello CA, Reichlin S, Lee SL and Lechan RM (1990) Intrinsic pituitary interleukin-1 $\beta$ is induced by bacterial lipopolysaccharide Endocrinology 126 3053-3058

Krüger BA, Trakshel GM, Sluss PM and Maines MD (1991) Cyclosporinmediated depression of luteinizing hormone receptors and heme biosynthesis in rat testes: a possible mechanism for decrease in serum testosterone Endocrinology $1292647-2654$
Mandl AM and Zuckerman S (1952) Cyclical changes in the number of medium and large follicles in the adult rat ovary Journal of Endocrinology 18 341-346

Morrison DC and Ryan JL (1987) Endotoxins and disease mechanisms Annual Review on Medicine 38 417-432

Raetz CRH, Ulevitch RJ, Wright SD, Sibley CH, Ding A and Nathan CF (1991) Gram negative endotoxin: an extraordinary lipid with profound effects on eukaryotic signal transduction FASEB Joumal 5 2652-2660

Rivier C (1990) Modulation of the rat pituitary and gonadal activity by factors from the endocrine and immune axes. In Neuroendocrine Regulation of Reproduction, pp. 285-293 Eds SSC Yen and WW Vale. Serono Symposia, Norwell, MA

Rivier C and Vale W (1990) Cytokines act within the brain to inhibit luteinizing hormone secretion and ovulation in the rat Endocrinology 127 849-856

Roby KF and Terranova PF (1990) Effects of tumor necrosis factor- $\alpha$ in vitro on steroidogenesis of healthy and atretic follicles of the rat: theca as a target Endocrinology $1262711-2718$

Rothwell NJ (1991a) The endocrine significance of cytokines Journal of Endocrinology 128 171-173

Rothwell NJ (1991b) Functions and mechanisms of interleukin-1 in the brain Trends in Pharmacological Sciences 12 430-436

Sancho-Tello M, Perez-Roger I, Imakawa K, Tilzer I and Terranova PE (1992a) Expression of tumor necrosis factor- $\alpha$ in the rat ovary Endocrinology 130 1359-1364

Sancho-Tello M, Chen T-Y, Clinton TK, Lyles TK, Moreno RF, Tilzer C, Imakawa $K$ and Terranova PF (1992b) Evidence for lipopolysaccharide binding in human granulosa-luteal cells Journal of Endocrinology 135 571-578

Sikka SC, Bhasin S, Coy DC, Koyle MA, Swerdloff RS and Rajfer J (1988) Effects of cyclosporine on the hypothalamic-pituitary-gonadal axis in the male rat: mechanism of action Endocrinology 123 1069-1074

Spangelo BL, Judd AM, Isakson PC and MacLeod RM (1989) Interleukin-6 stimulates anterior pituitary hormone release in vitro Endocrinology $\mathbf{1 2 5}$ 575-577

Spangelo BL, Judd AM, Isakson PC and MacLeod RM (1991) Interleukin-6 release from rat anterior pituitary cells in vitro Endocrinology 128 2685-2692

Vankelecom H, Carmeliet P, Van Damme J, Biuliau A and Denef C (1984) Production of interleukin- 6 by folliculostellate cells of the anterior pituitary gland in histiotypic cell aggregate culture system Neuroendocrinology 49 102-106

Welschen R (1973) Amounts of gonadotrophins required for normal follicular growth in hypophysectomised adult rats Acta Endocrinologica 72 137-155

Welschen R and Rutte $\mathbf{M}$ (1971) Ovulation in adult rats after treatment with pregnant male serum gonadotrophin during oestrus Acta Endocrinologica 68 $41-49$

Yamaguchi M, Sakata M, Matsuzaki N, Koike K, Miyake A and Tanizawa $O$ (1990a) Induction by tumor necrosis factor-alpha of rapid release of immunoreactive and bioactive luteinizing hormone from rat pituitary cells in vitro Neuroendocrinology 52 468-471

Yamaguchi M, Matsuzaki N, Hirota K, Miyake A and Tanizawa O (1990b) Interleukin- 6 possibly induced by interleukin- $1 \beta$ in the pituitary gland stimulates the release of gonadotropins and prolactin Acta Endocrinologica 122 201-205 